\title{
Automatic Extraction of SEMANTic ROLES IN SUPPORT VERB CONSTRUCTIONS
}

\author{
Ignazio Mauro Mirto \\ Department of Culture e società, Università di Palermo, Italy
}

\begin{abstract}
This paper deals with paraphrastic relations in Italian. In the following sentences: (a) Max strappò delle lacrime a Sara 'Max moved Sara to tears' and (b) Max fece piangere Sara 'Max made Sara cry', the verbs differ syntactically and semantically. Strappare 'tear/rip/wring' is transitive, fare 'have/make' is a causative, and piangere 'cry' is intransitive. Despite this, a translation of $(a)$ as $(b)$ is legitimate and therefore (a) is a paraphrase of $(b)$. In theoretical linguistics this raises an issue concerning the relationship between strappare and fare/piangere in Italian, and that in English between move and make. In computational linguistics, can such paraphrases be obtained automatically? Which apparatus should be deployed? The aim of this paper is to suggest a pathway with which to answer these questions.
\end{abstract}

\section{KEYWORDS}

Paraphrase, Entailments, Meaning Extraction, Automatic Detection of Semantic Roles.

\section{INTRODUCTION}

The Italian sentences below introduce the main phenomenon addressed in this paper, i.e. paraphrases:

$$
\begin{array}{ccc}
\text { La donna } & \text { arrestò } & \text { l'uomo } \\
\text { the woman } & \text { arrested } & \text { the man }
\end{array}
$$

$\begin{array}{cccc}\text { La donna } & \text { mise } & \text { l'uomo } & \text { agli arresti } \\ \text { the woman } & \text { put } & \text { the man } & \text { at.the arrest.PL }\end{array}$

'The woman put the man under arrest'

$$
\begin{array}{cccc}
\text { La donna } & \text { trasse } & \text { in arresto } & \text { l'uomo } \\
\text { the woman } & \text { got } & \text { in arrest.SG } & \text { the man }
\end{array}
$$

'The woman placed the man under arrest'

The preceding examples have in common the noun phrases la donna 'the woman' and l'uomo 'the man'. On the surface, they differ in the verbs deployed, which are arrestare 'arrest', mettere 'put', and trarre 'draw/get', and in the number of constituents, because (1) has no prepositional phrase (variations in register and information structure are irrelevant here). Despite these differences, the three sentences share a paraphrastic relationship. That is, the truth of any of them guarantees the truth of the other two. In computational linguistics (CL), such data sets raise the following questions: (a) can these truth values be obtained automatically?, and (b) which apparatus should be deployed? This paper aims to suggest a pathway by which to answer these questions. 
International Journal on Natural Language Computing (IJNLC) Vol.10, No.3, June 2021

\section{Paraphrases and Semantic Roles}

For our purposes, paraphrases should be defined as in [4] (: 108; for entailments between sentences, rather than propositions, see [1]: 29):

Two sentences may be said to be paraphrases of each other if and only if they have the same set of entailments; or, which comes to the same thing, if and only if they mutually entail each other so that whenever one is true the other must also be true.

Moreover, paraphrases are approached in a Harrisian spirit, that is, by keeping constant as far as possible the signifier and the signified (see [3]). Specifically, sentences (1) to (3) above only contain five content morphemes.

It seems reasonable to suggest that sets of sentences of this type are extremely common in any language. For example, a similar set obtains by employing the content morphemes envy and neighbour. Such a set could include the following five sentences: My neighbours envy her, She is envied by my neighbours, My neighbours are envious of her, It is my neighbours who envy her, and Those who envy her are my neighbours. With such sets, software which is capable of extracting truth values, and therefore the logical entailments generated by the underlying propositions, would be valuable for a number of tasks, including paraphrase recognition and paraphrase generation.

In order to detect such entailments between two or more sentences, a tool will be proposed in this paper (named NLP ${ }^{\mathrm{YtalY}}$ ) which extracts pairings by establishing matches between participants (broadly speaking, referential expressions) and semantic roles. Such pairings are formed by argument-predicate relations and they count as units of meaning. Table 1 illustrates these pairings in relation to sentence (1) (The woman arrested the man):

Table 1: Noun-CSR pairings in (1)

\begin{tabular}{lccc}
\hline 1. & DONNA & $=$ & $>$ s/he who arrests $<$ \\
\hline 2. & UOMO & $=$ & $>$ s/he who is arrested $<$ \\
\hline
\end{tabular}

The semantic representation above uses the symbol $=$ to equate a noun (which represents a participant in e.g. an event) with a semantic role. The latter, expressed with a notation deploying inverted single guillemets $(>\ldots<)$, has been termed as cognate semantic role (henceforth CSR, see [4], [5]) because a verb, which is etymologically related (as with Cognate objects) to the predicate licensing arguments, is employed (suppletive morphemes may be necessary, see below). The semantic core of (1) is thus decomposed into two units of meaning, each expressed as pairings between a (pro)noun and a CSR. In the transitive (1), distinct participants correspond to distinct referential expressions, thus the number of pairings supplies information related to entity extraction.

The other possible reading of (1), with reversed CSRs, i.e. the pairings DONNA $=$ arrestee and $\mathrm{UOMO}=$ arresting (i.e. The man arrested the woman), is rather unlikely but possible. However, since this interpretation can be achieved only via verbal emphasis (on la donna), the software discards it by detecting the following syntactic functions and CSRs: the NP la donna is identified as the subject and it is, therefore, associated with the active form arrests. Similarly, the NP l'uomo, the direct object, is associated with the passive form is arrested. 


\section{The Raison D'Être Of The Pairings}

Since the logical notation in Table 1 appears "as if it is 'stating the obvious'" ([4]: 139), the four cases below are provided to illustrate a number of advantages deriving from such a representation of meaning.

Let us first consider the pair in (4) and (5):

$\begin{array}{lll}\begin{array}{l}\text { L'uomo } \\ \text { the man }\end{array} & \begin{array}{l}\text { venne } \\ \text { came }\end{array} & \begin{array}{c}\text { puntuale } \\ \text { on time }\end{array} \\ \begin{array}{l}\text { L'uomo } \\ \text { the man }\end{array} & \begin{array}{l}\text { venne } \\ \text { came }\end{array} & \begin{array}{c}\text { arrestato } \\ \text { arrested }\end{array}\end{array}$

'The man was arrested'

In sentence (4), the verb venne expresses movement. It licenses an argument and assigns the CSR $>$ s/he who comes $<$ to it. On the other hand, in (5), venne is not a verb of movement. The pair demonstrates that the mere occurrence of a verb does not guarantee the assignment of a CSR, which instead depends on the verb's valence and its syntactic function (cf. The crowd went wild vs. The crowd went there). Venne is the main verb in (4), whilst in (5), which is one of the passive counterparts of (1), venne is an auxiliary verb and its valence is therefore blank. Pair (4)(5) provides a reason why the tool must be capable of detecting the verb function.

Secondly, by expressing sentence meaning as indicated in Table 1, some homonymy problems (WSD) can be efficiently treated. For example, the Italian word rombo, out of context, belongs to three distinct semantic fields: rumble/roar (noise), rhombus (geometry), and turbot/brill (fish):

Sentii un rombo

'I heard a rumble'

In relation to the direct objects of (6), (7), and (8), the software returns the pairings in Table 2, thus paving the way for solutions in case of lexical ambiguity:

Table 2: Noun-CSR pairings for direct objects in (6) to (8)

\begin{tabular}{|l|cll|c|}
\cline { 4 - 4 } \multicolumn{2}{l|}{} & \multicolumn{1}{c|}{ HYPERNYM } \\
\hline$(6)$ & ROMBO & $=$ & > what is heard $<$ & noise \\
\hline$(7)$ & ROMBO & $=$ & > what is drawn $<$ & drawing/quadrilateral \\
\hline$(8)$ & ROMBO & $=$ & > what is eaten $<$ & food \\
\hline
\end{tabular}

Thirdly, pairs of sentences such as (9) and (10), i.e. with a sequence of words in common, illustrate how CSRs lend themselves well to the representation of meaning:

(9) They want him

(10) They want him to leave

On the surface, sentence (10) appears to be formed by (9) plus the infinitive 'to leave'. However, this likeness is deceptive: the sentences have distinct structures and they convey distinct meanings. Noun-CSR pairings express this semantic difference in a simple way: whilst the direct 
International Journal on Natural Language Computing (IJNLC) Vol.10, No.3, June 2021

object of (9), i.e. him, is > he who is wanted<, that of (10) is >he who leaves<. This is so because in (9) him is licensed by want, whilst in (10) him is licensed by leave.

Pairs such as (9)-(10) occur also in Italian:

Leo prese il bambino

'Leo took the child'

Leo prese il bambino a schiaffi 'Leo slapped the boy'

Sentence (12) seems to be formed by joining the words in (11) to the prepositional phrase $a$ schiaffi (literally: 'to slaps'). As the translations reveal, however, the sentence structures differ: the direct object il bambino 'the boy' is an argument of prendere 'take' only in (11), whereas in (12) prendere plays no role in the assignment of CSRs.

Last, let us recall the claim that "transformations do not change meaning", made in early versions of Chomsky's grammar and later dismissed owing to counterevidence originating from quantifier scope (see Newmeyer 1983: 58). For example, on account of the quantifier ogni 'each/every', the active sentence in (13), which is ambiguous due to distinct distributive readings, does not carry the same meaning(s) as its passive counterpart in (14):

(13) Ogni ragazza ama un ragazzo

Un ragazzo è amato da ogni ragazza
'Each girl loves a boy'

'A boy is loved by each girl'

The tool proposed in this paper returns the following pairings for (13):

Table 3: Noun-CSR pairings in (13)

\begin{tabular}{lllc}
\hline 1. & RAGAZZA & $=$ & $>$ s/he who loves $<$ \\
\hline 2. & RAGAZZO & $=$ & $>$ s/he who is loved $<$ \\
\hline
\end{tabular}

As for (14), the results are those in Table 4, which are identical to those above:

Table 4: Noun-CSR pairings in (14)

\begin{tabular}{lllc}
\hline 1. & RAGAZZO & $=$ & $>$ s/he who is loved $<$ \\
\hline 2. & RAGAZZA & $=$ & $>$ s/he who loves $<$ \\
\hline
\end{tabular}

Prior to further elaboration of the pairings in Tables 3 and 4, let us consider the relationship between sentences with ordinary verbs, e.g. Sara smiled at him, and sentences with support verbs, e.g. Sara flashed him a smile. A comparison helps us understand how articles may block entailments. The second sentence entails the first: if Sara flashed him a smile, then Sara smiled at him. However, the opposite is not necessarily true, and on account of the article, since Sara smiled at him remains true even when Sara smiles repeatedly, not just once. Intuitively, however, these sentences appear semantically close. CSRs confirm the correctness of the intuition and permit the tool to identify the common core of the sentences: both yield the same unit of meaning, i.e. the pairing Sara $=>$ she who smiles $<$. Determiners, e.g. the indefinite articles and ogni 'each', function as quantifiers, which can be considered as function morphemes. CSRs permit the latter to be ignored and, as a result, the pairings in Tables 3 and 4 are identical.

Concluding this summary of the rationale for representing meaning relationally, i.e. through noun-CSR pairings, it is of note that each CSR corresponds to an equative sentence the value of which is true, that is, a Boolean term. For example, the predication in He laughed makes the equative sentence > he is the one who laughs < true (this Boolean value holds regardless of 
polarity, when negative; the latter will be treated at a later stage in the computational process). Thus, the semantic core of a sentence can be measured, in terms of quantity (as units of meaning) and of quality (by knowing, given a certain state of affairs, who-does-what-to-whom).

\section{A Paraphrase with Eseguire as a Support Verb}

Another Italian sentence to be added to the paraphrastic set in (1) to (3) is shown in (15):

$\begin{array}{cccc}\text { La donna } & \text { eseguì } & \text { l'arresto } & \text { dell'uomo } \\ \text { the woman } & \text { carried out } & \text { the arrest } & \text { of.the man }\end{array}$

'The woman arrested the man'

This sentence can be passivised and it is therefore transitive. However, the following can be demonstrated: (a) the verb eseguire 'perform/execute' licenses no arguments and it consequently assigns no CSRs; (b) the predicate licensing arguments is the NP l'arresto; (c) the latter NP assigns CSRs without receiving any. In other words, (15) is an instance of the support verb construction. The post-verbal noun arresto 'arrest' functions as a two-place predicate and its arguments are the same which the cognate verb arrestare 'to arrest' licenses. That which follows is that (15) can be semantically represented by the same pairings contained in Table 1, and it is itself a paraphrase of any of the sentences in the initial paraphrastic set.

\section{ASYMMETRIC ENTAILMENTS}

Logicians distinguish between two types of entailment: symmetric entailment (i.e. two-way) and asymmetric. In the former type, the truth of sentence $X$ guarantees the truth of sentence $Y$, and vice versa. In the latter, the truth of sentence $\mathrm{X}$ still guarantees the truth of sentence $\mathrm{Y}$, but the opposite is not true.

The CSR-based entailments which have been explored thus far are those related to the paraphrastic set formed by (1), (2), (3), (15) and they are all symmetric. However, any of the sentences in the former set establishes an asymmetric type of entailment in relation to (16) below:

$$
\begin{array}{ccc}
\begin{array}{c}
\text { Faceste } \\
\text { made. } 2^{\text {nd }} . P L
\end{array} \text { arrestare } & \text { l'uomo arrest } & \text { dalla donna } \\
\text { the man } & \text { by.the woman } \\
\text { 'You had the man arrested by the woman' }
\end{array}
$$

Sentence (16) exemplifies the causative clause type of Italian with the verb fare 'have/make'. Compared to e.g. (1), (16) presents an additional argument, the causer, i.e. a covert $2^{\text {nd }}$ person and plural subject pronoun (voi 'you'). This sentence entails (1), (2), (3) and (15), and its semantic representation therefore includes the pairings listed in Table 1 . However, on account of the additional semantic role being assigned by fare to the causer, i.e. the subject, (1) does not entail (16). As Table 5 illustrates, the paraphrasing tool automatically extracts the same pairings found for e.g. (1), but also the pairing between the covert subject and its semantic role 'cause':

Table 5: Noun-CSR pairings in (16)

\begin{tabular}{lllc}
\hline 1. & DONNA & $=$ & $>$ s/he who arrests $<$ \\
\hline 2. & UOMO & $=$ & $>$ s/he who is arrested $<$ \\
\hline 3. & $2^{\text {nd }} \mathrm{PL}$ & $=$ & $>$ what brings about the arrest $<$ \\
\hline
\end{tabular}


The presence of pairing number 3 in Table 5 only permits asymmetric entailments between (16) and the group of sentences formed by (1), (2), (3), and (15).

\section{Grammatical Relations, Diathesis, AND CSRS}

In the sentences (1), (2), and (3), the noun uomo 'man' occurs within a noun phrase which fulfils the direct object function. In (15), however, the same noun is part of a prepositional phrase, the of-phrase dell'uomo, which functions as a complement (of the noun arresto) and is therefore optional. This difference in grammatical relation is independent of the semantic role which the noun conveys: the phrases l'uomo and dell'uomo are paired to the same CSR. In a parallel way, the noun donna 'woman' is the subject of (1), (2), and (3), but it occurs within a by-phrase in (16). Again, we can observe distinct grammatical relations which convey the same CSR. This is a wellknown fact in theoretical linguistics.

How does the tool extract the same CSR from distinct grammatical relations? For each clause type, a dedicated function was written (the system uses Python 3.8 and TreeTagger; to date, it is rule-based only. We know that rule-based systems are out-of-date and we also believe that statistical-based approaches are essential. No references will be provided of the latter because in our opinion they hardly compare with the former. We agree with [2] when the authors maintain that "computational semantics is destined to fail if it is not supported by a clear understanding of the relevant underlying linguistic phenomena involved in the task to which it is applied"). This function returns the correct pairings by exploiting the morphosyntactic cues which assist the identifying of various phrase types. For example, consider the passive in (17):

$$
\begin{array}{cccc}
\text { L'uomo } & \text { fu } & \text { arrestato } & \text { dalla donna } \\
\text { the man } & \text { was } & \text { arrested } & \text { by.the woman }
\end{array}
$$

'The man was arrested by the woman'

The proposed tool detects four distinct types of diathesis (active, passive, middle reflexive, and middle non-reflexive). Sentence (17) will be recognised as a passive counterpart of (1): the nouns uomo and donna will then be paired to the same CSRs, as is the case with the active counterpart. Again, the tool will extract the semantic representation as Table 1 above.

\section{The Multiple Paraphrase Phenomenon}

Paraphrases have been previously dealt with by initially selecting source sentences, then extracting the noun-CSR pairings which they express. Let us now reverse this approach and take the pairings as the starting point of the procedure. A certain number of sentences, whose semantic interpretations are amenable to one or more of the initial pairings, will then be identified. These sentences will form a paraphrastic set. At this juncture, a probing question arises: how large will it be? It can be argued that the larger the set, the more effective the procedure will be in relation to paraphrase recognition and generation.

Since the pairings in Table 1 have already been correlated with a number of sentences, they will make the above task simpler. Two types of correlations, and consequently two distinct sets, have to be distinguished. On the one hand, source sentences will be identified expressing exactly the pairings in Table 1. Each sentence in this set, let us call it Set A, will thus establish symmetric entailments with the other sentences in the same set. On the other hand, a distinct set will obtain, let us call it Set B, with source sentences establishing asymmetric entailments with each of the sentences in Set A. 
The sentences which have previously been connected to the pairings in Table 1 are: (a) those in the initial group, namely (1), (2), and (3); (b) sentence (15), a support verb construction; and (c) sentence (17), one of the passive counterparts of (1). An additional passive example is (18) below. This set is characterised by symmetric entailments:

$\begin{array}{cccccc}\text { L'uomo } & \text { fu } & \text { posto } & \text { sotto } & \text { arresto } & \text { dalla donna } \\ \text { the man } & \text { was } & \text { placed } & \text { under } & \text { arrest } & \text { by.the woman }\end{array}$

'The man was arrested by the woman'

Set B includes the causative (16), which also expresses both pairings, but it establishes an asymmetric entailment with any sentence in Set A because (16) expresses an additional pairing (see Table 5). Set B also comprises (5), L'uomo venne arrestato 'The man got arrested', because (5) also generates an asymmetric entailment, although for the opposite reason, because it only expresses one of the pairings in Table 1. Thus far, then, eight sentences have been illustrated which are related to the pairings in Table 1, either symmetrically (set A) or asymmetrically (Set B). How many other Italian sentences can be inserted into the sets? The following exposition will demonstrate how this number will grow dramatically by taking any of the eight sentences and by modifying it with-one of the following operations, which preserve CSRs: (a) diathesis; (b) tense, (c) mood, and (d) information structure. Of note, by no means do such operations exhaust the ways by which Sets A and B increase in number; they are illustrated simply to provide a basic idea of how the growth of such sets can be exponential.

Only the increase in the size of Set A will be illustrated. The process may still be exemplified by employing sentence (1), i.e. La donna arrestò l'uomo 'The woman arrested the man'. Also, for the sake of brevity only examples regarding (d), i.e. information structure, will be supplied.

Diathesis: A change in diathesis, from active to passive, has already been illustrated in (17). Other additional sentences will derive from passives with the auxiliary venire (see (5)) and from a number of impersonal and antipassive variants.

Tense: The verb in sentence (1) is a passato remoto, which can be modified to e.g. presente, passato prossimo, or trapassato prossimo, and by leaving the CSRs unvaried. Each sentence normally allows for eight different tenses in the indicative.

Mood: The verb of (1), in the indicative, can be changed into a subjunctive or a conditional without modifying its CSRs. This generates six additional sentences.

Information structure: Each of the NPs of (1) can be clefted for emphasis, as (19) to (21) illustrate (in (19) and (20) the subject is clefted in two distinct ways). As these sentences also express both the pairings in Table 1, they increase the size of Set A:

(19) Fu la donna che arrestò l'uomo

'It was the woman who arrested the man'

(20) Fu la donna ad arrestare l'uomo

'It was the woman who arrested the man'

(21) Fu l'uomo che la donna arrestò

'It was the woman who arrested the man'

The following four sentences obtain with pseudoclefts; they also express both the pairings in Table 1: 
(22) Quella che arrestò l'uomo fu la donna

'The one who arrested the man was the woman'

(23) Quello che la donna arrestò fu l'uomo

'The one who the woman arrested was the man'

(24) Ciò che la donna fece fu arrestare l'uomo

'What the woman did was arrest the man'

(25) Ciò che la donna fece all'uomo fu arrestarlo

'What the woman did to the man was arrest him'

Other variants of (1), with marked linear orders signalling emphasis of a constituent, are displayed below (consider that Italian is an SVO language). The sentences in (26) and (27) topicalise the direct object (in bold), whilst those in (28) to (31) exemplify left and right dislocation (the translations provided do not convey the emphasis). Sentences (28) to (31) include a resumptive clitic which is drawn from the direct object series, the singular and masculine $l o$ :

La donna l'uomo arrestò!

(SOV)

'The woman arrested the man!'

(27) L'uomo la donna arrestò!

(OSV)

'The woman arrested the man!'

(28) La donna lo arrestò l'uomo

'The woman arrested the man'

(SVO)

(29) L'uomo la donna lo arrestò

(OSV)

'The woman arrested the man'

La donna l'uomo lo arrestò

(SOV)

'The woman arrested the man'

L'uomo lo arrestò la donna

'The woman arrested the man'

(OVS)

In conclusion, a number of operations on (1), related to diathesis, tense, mood, and information structure, increase the size of Set A considerably. Generally, an unmarked, elementary sentence featuring three constituents will yield a cluster of approximately 30 related sentences.

Let us now turn our attention to sentence (15) as a further example. Being a support verb construction, (15) cannot be considered an elementary sentence, because its predication is distributed over two constituents: the VP and the post-verbal NP. As a consequence, a symmetric entailment with (1) can be obtained only by adding a prepositional phrase, i.e. dell'uomo 'of the man'. This increase in the number of constituents will expand the sets. Specifically, on account of the extra constituent, the cluster of sentences related to information structure will be higher.

Support verb constructions contribute to enlarging the sets in yet another way. It is well-known that, by replacing the verb of a support verb construction, the semantic roles assigned remain unvaried, whilst changes may be observed in e.g. register. An example of this can be found in 
International Journal on Natural Language Computing (IJNLC) Vol.10, No.3, June 2021

(32), typical of bureaucratese, and (33), higher in register. On the other hand, (34) can be considered informal:

\author{
La donna effettuò l'arresto dell'uomo \\ 'The woman arrested the man' \\ La donna compì l'arresto dell'uomo \\ 'The woman arrested the man' \\ La donna fece l'arresto (dell'uomo) \\ 'The woman made the arrest (of the man)'
}

Thus, by adding (15) to the paraphrastic set, the enlargement process observed above recurs, because the cluster of related sentences, including passives, clefts, pseudoclefts, etc., will enlarge the size of the set yet again. The same increase will take place with the inclusion of each of the variants in (32) to (34). Sentences (2), (3), and (18) will also have to be included, and the process will repeat itself: each of them will bring with it a new cluster of supplementary sentences.

To conclude, a multiple paraphrase phenomenon will be observed by starting the procedure with pairings such as those in Table 1. A couple of pairings permit the construction of large paraphrastic sets, formed by hundreds of sentences which are all interrelated by symmetric and asymmetric entailments. Needless to say, all the sentences in this set can be automatically generated.

\title{
8. Conclusions
}

In those fields of computational linguistics dealing with meaning extraction, the main difficulty which researchers face is probably the same as that in the field of semantics, namely the very definition of meaning. Scholars working on natural languages know very well that this metalinguistic term can refer to multiple facets of the interpretations generated by sentences (utterances are more complex for obvious reasons). The word meaning, too vague, begs for precision. This study has attempted to reduce its complexity and express meaning in a format compatible with computational tools. The investigation domain has been restricted to sentence meaning and contributions from pragmatics have been excluded. Meaning has been rendered with logical formulae, which are conceived of relationally, i.e. as pairings between participants and semantic roles. For any given sentence (unstructured text), participants are extracted from either noun phrases or prepositional phrases functioning as arguments. Semantic roles are instead expressed by employing the content morpheme of phrases, of any kind, functioning as predicates. This method produces as many units of meaning as the number of arguments occurring in the sentence. The representation of meaning which such units provide paves the way for paraphrase recognition and generation. The final step has consisted in going beyond the single sentence: the pairings can be employed to establish relations between sentences, in terms of truth values, entailments, and paraphrases.

The pairings which the proposed method produces can be used in both directions, like a pathway. Currently, the tool can parse a sentence and extract the pairings. A development could be to take the pairings as the starting point and arrive at sets whose members are sentences conveying one or more of the initial pairings. These sets are susceptible to being used for various purposes, from paraphrase recognition to assisted translation.

Particular attention has been paid to support verb constructions, that is, a clause type whose syntax-semantics interface is characterised by CSRs which typically come from the post-verbal 
International Journal on Natural Language Computing (IJNLC) Vol.10, No.3, June 2021

NP (in case of unmarked word order). In sentences (15), (32), (33), and (34), it is the post-verbal NP which functions predicatively and is therefore responsible for the assignment of CSRs. However, it has been suggested that in other clause types CSRs may originate from prepositional phrases, as is the case in (2), (3), (12), and (18).

The method outlined in this paper permits the connecting of sentences which share the participants but differ in all other aspects. For example, the tool presented above recognizes a causative sentence such as Max fece piangere Sara 'Max made Sara cry' as a symmetric paraphrase of Max strappò delle lacrime a Sara 'Max moved Sara to tears'. The pairing 'Sara = $>$ she who cries $<$ ' is extracted from both sentences. However, only in the former sentence does this pairing originate from the cognate verb piangere 'cry', whilst in the latter its origin is in the post-verbal NP delle lacrime. This procedure requires a data structure with a suppletive CSR linking cry to tears 'lacrime'.

\section{REFERENCES}

[1] Cruse, A. (2000), Meaning in Language, Oxford University Press, Oxford.

[2] Gliozzo A., C. Strapparava (2009), Semantic Domains in Computational Linguistics, Springer, London/New York.

[3] Harris, Z. S. (1981), Papers on Syntax, H. Hiż (ed.), D. Reidel Publishing Company, London.

[4] Hurford J. R., B. Heasley, (1983), Semantics. A coursebook, Cambridge University Press, Cambridge.

[5] Mirto, I. M. (2007), Dream a little dream of me: Cognate predicates in English, Actes du 26e Colloque international Lexique Grammaire, Institut Gaspard Monge, Paris, 121-128. On-line:

[6] Mirto, I. M. (2011), Oggetti interni e reaction objects come nomi predicativi di costrutti a verbo supporto, Écho Des Études Romanes, 7, 1, 22-47.

[7] Newmeyer, F. J. (1983), Grammatical Theory: Its limits and its possibilities, University of Chicago Press, Chicago.

\section{AUTHOR}

Ignazio Mauro Mirto (Ph.D. Cornell University) is Associate Professor of General Linguistics at the University of Palermo. His current work encompasses the area of morphosyntax, information structure, and determiners as inflectional morphemes for the syntactic closure of noun phrases functioning as arguments.

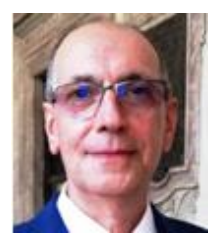

